\title{
Alterations in intestinal serosal microcirculation precipitated by the Pringle manoeuvre
}

\author{
Lucinda Shen, ${ }^{1,2}$ Zühre Uz, ${ }^{1,3}$ Can Ince, ${ }^{1,2}$ Thomas van Gulik ${ }^{4}$
}

'Department of Translational Physiology, Amsterdam UMC, Amsterdam, The Netherlands ${ }^{2}$ Department of Intensive Care, Erasmus MC, Rotterdam, The Netherlands

${ }^{3}$ Department of Experimental Surgery, Amsterdam UMC, Amsterdam, The Netherlands ${ }^{4}$ Department of Surgery, Academic Medical Center, Amsterdam, The Netherlands

\section{Correspondence to}

Professor Thomas van Gulik, t.m.vangulik@amc.nl

Accepted 7 December 2018

Check for updates

(c) BMJ Publishing Group Limited 2019. No commercial re-use. See rights and permissions. Published by BMJ.

\begin{tabular}{l}
\hline To cite: Shen L, Uz Z, \\
Ince C, et al. BMJ Case \\
Rep 2019;12:e228111. \\
doi:10.1136/bcr-2018- \\
228111
\end{tabular}

\section{DESCRIPTION}

The Pringle manoeuvre can be applied during liver resection to reduce blood loss. During this procedure, inflow of blood into the liver is occluded through clamping of both the portal vein and hepatic artery in the hepatoduodenal ligament. This induces portal congestion in the splanchnic bed and causes collateral blood flow. Experimental and clinical studies have shown an association between the application of the Pringle manoeuvre and intestinal dysfunction. ${ }^{12}$ Herein, we present a case report showing intraoperative intestinal serosal microcirculatory alterations resulting from the Pringle manoeuvre.

A 51-year-old man with a history of chronic hepatitis B presented with hepatocellular carcinoma and was admitted to our department for elective extended right hepatectomy. During surgery, the patient received $1000 \mathrm{~mL}$ of colloids (Tetraspan 6\%) to correct for blood loss, in addition to general fluid therapy. Systemic parameters such as heart rate, blood pressure and mean

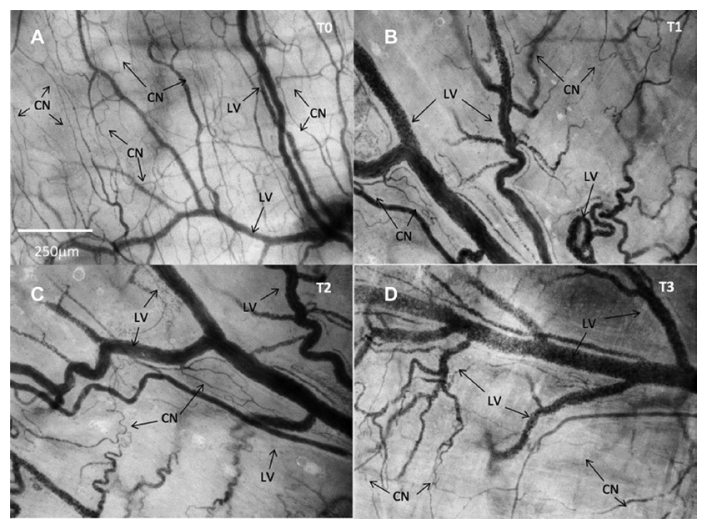

Figure 1 Screenshots of incident dark field imaging of the intestinal microcirculation at four different timepoints. The arrow heads indicate capillary networks (CN) and large vessels (LV). (A) Image acquired immediately following skin incision. Microcirculatory parameters: total vessel density (TVD) $33.75 \mathrm{~mm} / \mathrm{mm}^{2}$, perfused vessel density (PVD) $33.69 \mathrm{~mm} / \mathrm{mm}^{2}$, portion of perfused vessel (PPV) $99.81 \%$ and microvascular mean flow index (MFI) 3.0. (B) At the end of the Pringle, after $20 \mathrm{~min}$ of occlusion. Microcirculatory parameters: TVD $17.5 \mathrm{~mm} /$ $\mathrm{mm}^{2}$, PVD $14.4 \mathrm{~mm} / \mathrm{mm}^{2}$, PPV $80.73 \%$ and MFI 2.25. (C) Immediately following release of the Pringle manoeuvre. Microcirculatory parameters: TVD $19.42 \mathrm{~mm} / \mathrm{mm}^{2}$, PVD $17.3 \mathrm{~mm} / \mathrm{mm}^{2}$, PPV $89.05 \%$ and MFI 2.5. (D) At the end of surgery, before skin closure. Microcirculatory parameters: TVD $13.67 \mathrm{~mm} / \mathrm{mm}^{2}$, PVD $11.19 \mathrm{~mm} / \mathrm{mm}^{2}$, PPV $81.35 \%$ and MFI 2.67.

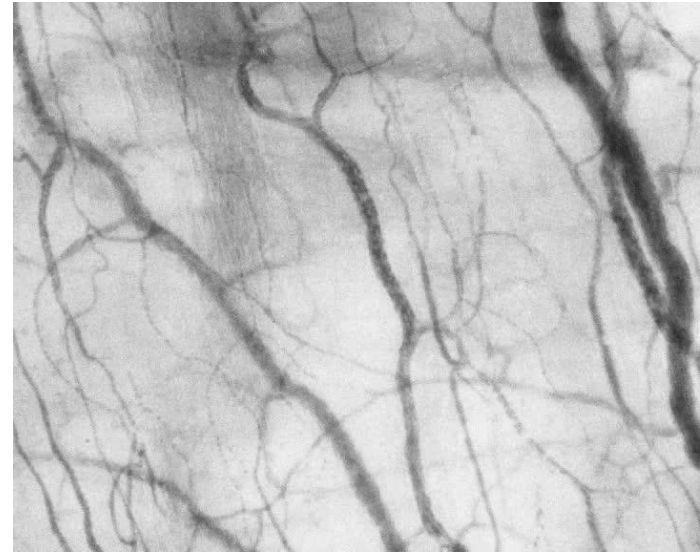

Video 1 Clip of incident dark field imaging of the intestinal serosal microcirculation at the TO. A dense capillary networks can be seen on the serosal surface of the jejunum. Continuous flow of red blood cells is observed in nearly all vessels.

arterial pressure remained at an acceptable standard throughout surgery and there were no intraoperative complications.

Intestinal serosal microcirculatory monitoring (IntMiMo) was carried out using incident dark field (IDF) imaging (CytoCam, Braedius Medical, Huizen, The Netherlands). The CytoCam is a handheld video-microscope that emits light at $548 \mathrm{~nm}$. This is absorbed by haemoglobin yielding

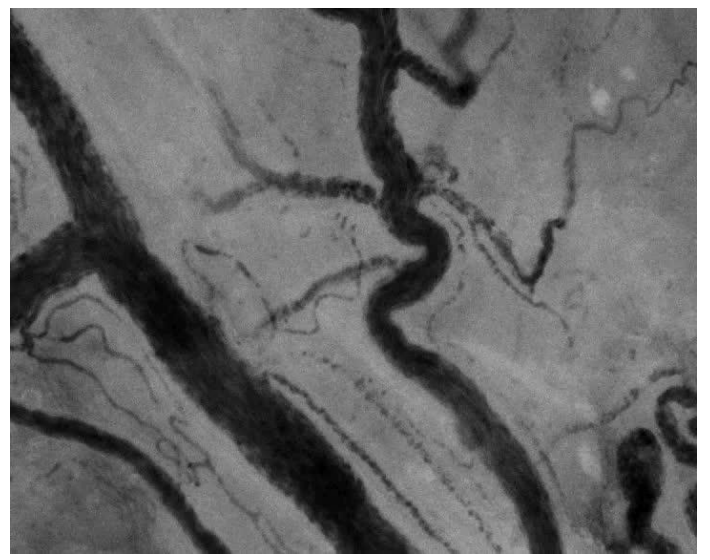

Video 2 Clip of incident dark field imaging of the intestinal serosal microcirculation at T1 The dense capillary network (CN) seen at TO have dissipated and areas of malperfusion become visible. Blood flow in the CNs is sluggish and shows an intermittent pattern. Large vessels are dilated and showed increase in blood flow when compared with $\mathrm{T} 0$, such that individual red blood cells are no longer identifiable. 


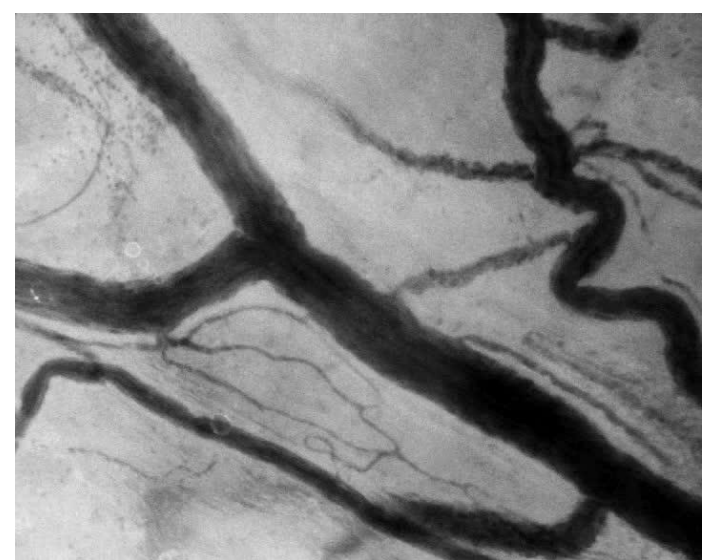

Video 3 Clip of incident dark field imaging of the intestinal serosal microcirculation at $\mathrm{T} 2$ restoration of blood flow is observed in the capillary networks. In the large vessel, the blood flow has further increased when compared with that of $\mathrm{T} 1$, such that the red blood cells have adopted a stripe formation.

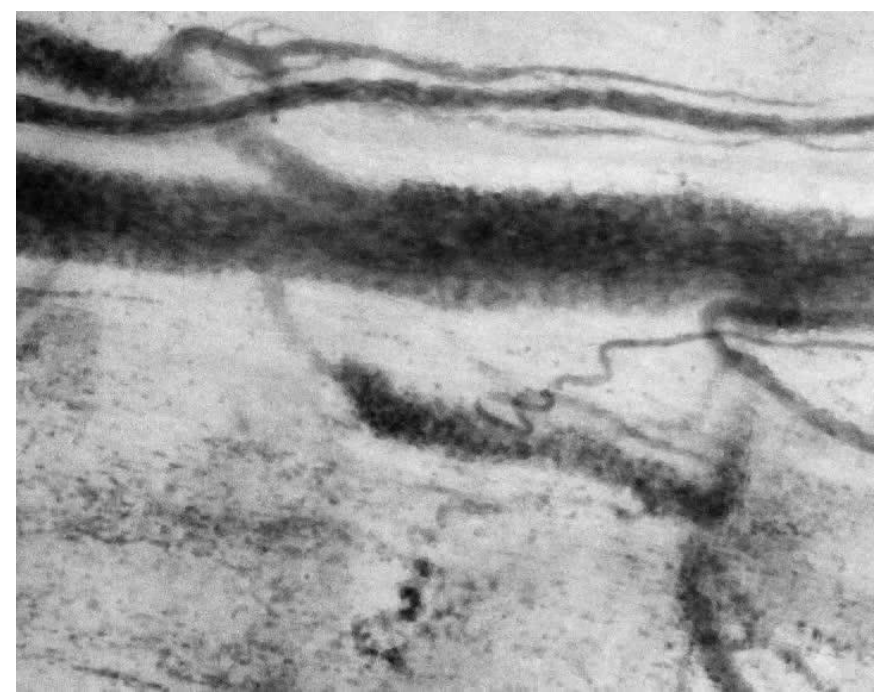

Video 4 Clip of incident dark field imaging of the intestinal serosal microcirculation at T3 Restoration of capillary networks is observed while larger vessels remain dilated. A greyish colour inside the vessels suggests dilution of red blood cells caused by the administration of colloids.

visibility to red blood cells (RBCs). ${ }^{3}$ The CytoCam was placed on the serosal surface of the jejunum $50 \mathrm{~cm}$ distally from the ligament of Treitz and IntMiMo was carried out at four different timepoints: immediately following skin incision (T0), at the end of the Pringle manoeuvre (after $20 \mathrm{~min}$ of occlusion) (T1), immediately after release of the Pringle manoeuvre (T2) and at the end of the operation before skin closure (T3). Analysis of IntMiMo was carried out offline using the software Automated Vascular Analysis V.3.0 (Microvision Medical, Amsterdam, The Netherlands).
The results showed a drop in microcirculatory density (total vessel density and perfused vessel density) and perfusion parameters (proportion of perfused vessels and microvascular mean flow index), between the baseline (T0) and the end of surgery (T3) (see legends of figure 1 and videos 1-4). Alterations of the intestinal serosal microcirculation can also be assessed visually. The dense capillary networks seen at baseline (T0) dissipated following the occlusion and reperfusion (T1, T2, T3), revealing areas of malperfusion. The temporary acute rise in portal venous pressure during the Pringle manoeuvre may have further contributed to these alterations. ${ }^{2}$ Following the administration of colloids, large plasma gaps and low RBC density became visible in the serosal microcirculation.

This report shows for the first time, intestinal serosal microcirculatory alterations in perfusion. Together with previous studies demonstrating intestinal epithelial damage and endotoxaemia subsequent to the Pringle manoeuvre, ${ }^{2}$ the visualisation of the intestinal microcirculation can further aid in the understanding of the pathophysiological changes in the intestines following portal occlusion and allows monitoring of the patient's intestinal perfusion status during liver resection.

Patient was discharged after 16 days in hospital. On outpatient examination at follow-up, no further complications were found incurring that the observed intestinal microcirculatory alterations had resolved following surgery.

\section{Learning points}

- Intraoperative application of the Pringle manoeuvre causes intestinal microcirculatory alterations.

- Intestinal serosal microcirculatory monitoring allows additional checks on the patient's intestinal perfusion status during liver surgery.

Contributors $L S$ was involved in the data collection of the microcirculatory images, the analysis of data using Automated Vascular Analysis and drafting of the final manuscript. ZU was also involved in the data collection, the interpretation of the collected data and drafting of the manuscript. Cl gave critical intellectual insight and aided in the drafting and approval of the final manuscript. TvG was involved in the data collection and the design of the case report. He also gave critical feedback on the interpretation of data. He was also involved in the drafting and the approval of the final manuscript.

Funding The authors have not declared a specific grant for this research from any funding agency in the public, commercial or not-for-profit sectors.

Competing interests None declared.

Patient consent Obtained.

Provenance and peer review Not commissioned; externally peer reviewed.

\section{REFERENCES}

1 Filos KS, Kirkilesis I, Spiliopoulou I, et al. Bacterial translocation, endotoxaemia and apoptosis following Pringle manoeuvre in rats. In: Injury, 2004:35-43.

2 Dello SA, Reisinger KW, van Dam RM, et al. Total intermittent pringle maneuver during liver resection can induce intestinal epithelial cell damage and endotoxemia. PLOS One 2012;7:e30539.

3 Ince C, Boerma EC, Cecconi M, et al. Second consensus on the assessment of sublingual microcirculation in critically ill patients: results from a task force of the European Society of Intensive Care Medicine. Intensive Care Med 2018;44:281-99. 
Copyright 2018 BMJ Publishing Group. All rights reserved. For permission to reuse any of this content visit https://www.bmj.com/company/products-services/rights-and-licensing/permissions/

BMJ Case Report Fellows may re-use this article for personal use and teaching without any further permission.

Become a Fellow of BMJ Case Reports today and you can:

- Submit as many cases as you like

- Enjoy fast sympathetic peer review and rapid publication of accepted articles

Access all the published articles

Re-use any of the published material for personal use and teaching without further permission

For information on Institutional Fellowships contact consortiasales@bmjgroup.com

Visit casereports.bmj.com for more articles like this and to become a Fellow 